\title{
The value of the ITS2 region for the identification of species boundaries between Alloxysta hyperparasitoids (Hymenoptera: Charipidae) of aphids
}

\author{
F.J. Frank VAN VEEN*, Robert BELSHAW and H. Charles J. GODFRAY
}

NERC Centre for Population Biology and Department of Biological Sciences, Imperial College London, Silwood Park Campus, Ascot, Berkshire, SL5 7PY United Kingdom

Key words. Alloxystinae; aphid; apparent competition; food web; hyperparasitoid; ITS2

\begin{abstract}
Alloxystinae are major secondary parasitoids of aphids, important in both their ecology and pest management. 2) Two radically differing views of alloxystine taxonomy exist in the literature, in one of which the group is very diverse, in the other it consists of a few variable species. 3) We sequenced a variable nuclear gene region (ITS2) for 28 specimens of a morphologically clearly defined group which, in one view belong to a single species and in the other to four species. We find that the four putative species each carry a different unique allele with no intraspecific variation. We show that the probability of the observed distribution of alleles under the assumption of a single interbreeding population is very small and we reject the view that all specimens belong to a single biological species. 4) We discuss the implications of our results for aphid - parasitoid community ecology and the biological control of aphids with parasitoids.
\end{abstract}

\section{INTRODUCTION}

Taxonomic problems can be a severe hindrance to ecological research. This is particularly true in community ecology where the basic unit of analysis is often the biological species and the presence of cryptic species and/or spurious species can cause huge problems in correct data inference. The difficulties often arise because the species concerned are small and have a limited number of diagnostic morphological characters. In these circumstances setting species boundaries can be hard and subject to different interpretations. The use of modern DNA-based molecular techniques can be an important tool for resolving these issues (Avise, 1994; Knowlton, 2000; Waters et al., 2001).

For the last eight years we have been studying quantitatively the community of aphids and their primary and secondary parasitoids at a site in the south of England (Müller et al., 1999). We are particularly interested in how pairs of species that do not directly interact may nevertheless have linked population dynamics by virtue of their shared natural enemies, a process termed apparent competition (Holt, 1977). We construct quantitative food webs to assess the potential importance of these indirect effects, but the success of this approach depends on correctly identifying the biological species present.

Aphid primary parasitoids are insects whose larvae develop as parasites of aphids eventually pupating inside the mummified skin of the dead aphid, creating the socalled mummy (Godfray, 1994). Some of the major taxonomic problems in this group have been resolved with electrophoretic studies (Pungerl, 1986; Atanassova et al., 1998). Secondary parasitoids attack the primary parasitoid larvae and can be thought of as the top predators in the aphid-parasitoid community. Of the 28 secondary parasitoid species listed by Müller et al. (1999) in our community, 18 belong to the Alloxystinae (Hymenoptera, Cynipoidea, Charipidae). There are two radically different opinions about the diversity of this group. In the only modern comprehensive review of the British species, Fergusson (1986) recognised few species, most of which were morphologically very variable and with a wide host range. The opposite view is represented by Evenhuis and co-workers (Evenhuis \& Barbotin, 1987 and references therein) who recognised many more species, each of which were relatively invariable with a narrow host range. Our studies of the biology of the alloxystines within our community have suggested that species have narrow host ranges and we have provisionally accepted this second view, also because this leads to the most conservative estimate of the potential for hyperparasitoid mediated indirect interactions. However, if the alternative is in fact correct, then this would make a major difference to how we interpret the structure of our food web.

Here we use molecular techniques to determine the species boundaries in one well-defined group of Alloxystinae, where we recognise three species in our community, but which according to Fergusson (1986) are all members of a single variable species. We sequenced the ITS 2 region of the rDNA of specimens of each species collected in or around our field site. To assess geographical variation, for two species we also sequenced specimens from Germany. Finally we also studied British and German specimens of a fourth taxon that does not appear in our food web but hyperparasitises the economically significant cabbage aphid and which also belongs to the same variable species according to Fergusson (1986).

\footnotetext{
* Corresponding author. E-mail: f.vanveen@imperial.ac.uk, fax: +44 1344873173.
} 
TABLE 1. Host details and localities of the Alloxysta specimens that were analysed. As = Ascot, Berkshire, UK; Ho = Hope, Derbyshire, UK; He = Henley, Oxfordshire, UK; Ba = Bayreuth, Germany. The location of our long-term community study is Ascot.

\begin{tabular}{|c|c|c|c|c|c|}
\hline Species & Plant & Aphid host & Parasitoid host & Sampling site & $\begin{array}{c}\text { Number of } \\
\text { specimens }\end{array}$ \\
\hline A. victrix & Vicia faba & Acyrthosiphon pisum & Aphidius ervi & As & $2 ㅇ ㅜ, 1 \delta$ \\
\hline A. victrix & Lotus uliginosus & A. pisum & Aphidius sp. & As & $2 q 9+$ \\
\hline A. victrix & Poa sp. & Sitobion sp. & Aphidius sp. & As & $4 ㅇ+ㅇ$ \\
\hline A. victrix & Deschampsia cespitosa & Sitobion sp. & Aphidius sp. & As & 1 운 \\
\hline A. victrix & Cirsium arvense & Uroleucon cirsii & Aphidius funebris & As & 1 인 \\
\hline A. tscheki & Cirsium palustre & Capitophorus carduinis & Aphidius matricariae & As & $4 ㅇ ㅜ, 10$ \\
\hline A. tscheki & Ribes alpinum & Cryptomyzus sp. & Aphidius ribis & $\mathrm{Ba}$ & $29, 1 \hat{0}$ \\
\hline A. tscheki & Picea sitchensis & Elatobium abietinum & Aphidius schimitscheki & As & 19 \\
\hline A. fuscicornis & Brassica sp. & Brevicoryne brassicae & Diaeretiella rapae & Ho & 19,230 \\
\hline A. fuscicornis & Brassica sp. & B. brassicae & D. rapae & $\mathrm{He}$ & $1 \delta$ \\
\hline A. fuscicornis & Brassica sp. & B. brassicae & D. rapae & $\mathrm{Ba}$ & $10^{\circ}$ \\
\hline A. leunisii & Cirsium arvense & Uroleucon cirsii & Aphidius funebris & As & $1 \%, 1$ 항 \\
\hline A. leunisii & C. arvense & U. cirsii & A. funebris & $\mathrm{Ba}$ & 1 우 \\
\hline
\end{tabular}

\section{MATERIAL AND METHODS}

\section{Taxonomic background}

The Charipidae is a morphologically uniform group of insects about $0.5-2 \mathrm{~mm}$ in total body length, all of which develop as secondary parasitoids of Homoptera. It is divided into two subfamilies, the Charipinae which attack parasitoids of psyllids, and the Alloxystinae, which attack parasitoids of aphids. In Europe the Alloxystinae comprise two genera, Phaenoglyphis and Alloxysta. Andrews (1978) catalogues the world species of Alloxystinae and lists 120 names for Palaearctic Alloxysta although a large fraction of these are likely to be synonyms. Alloxystines parasitise the primary parasitoids of aphids (which belong to the chalcidoid family Aphelinidae and the braconid subfamily Aphidiinae) and attack their hosts while the aphid is still alive, prior to mummification (in contrast to other secondary parasitoids that attack the mummy).

We worked with a group of morphologically very similar taxa that we refer to as the victrix group. They can be defined by the following set of characters: (i) closed radial cells; (ii) absence of carinae on propodeum; (iii) carinae present on pronotum, with area between them hairless; (iv) male antennae with segments 3 , 4 and 5 curved or emarginate (see Evenhuis, 1974 and Menke \& Evenhuis, 1991 for further details of alloxystine morphology). Fergusson (1986) treats the group as a single species, victrix Westwood, while we currently recognise four species by applying the criteria of Evenhuis and co-workers. Within the victrix group, individuals reared from different hosts can be distinguished by subtle characters such as the ratio of the lengths of antennal segments and body colour. Whether these differences are species diagnostic, or whether they merely reflect hostinduced phenotypic plasticity can only be resolved by studying genetic characters that are independent of the wasp's host. Fergusson also synonymised $A$. circumscripta Hartig with $A$. victrix but the structure of its pronotum, a character not used by Fergusson, shows it to be outside the victrix group and not closely related (Menke \& Evenhuis, 1991).

\section{Specimens analysed}

In our long-term study of an aphid-parasitoid community (Müller et al., 1999; unpublished data) we have reared three taxa of the A. victrix group that we have provisionally considered to be species. Specimens of each are included in this study as well as a fourth species found nearby but not in our study site. Table 1 is a full list of the specimens sequenced, their hosts, host aphids and host plants.

(i) victrix Westwood sensu stricto. The limited conception of this species is due to Evenhuis (1972, pers. comm.) but it is still the most polyphagous member of the genus, though the aphids whose parasitoids it attacks are all Macrosiphini. In our study site we have reared this species from 10 different hosts and found it to be quite variable, especially in colour. However, the colour variation seems to be correlated with host size. We included 11 specimens from three hosts spanning this variation.

(ii) leunisii Hartig. Evenhuis (1982) reared an alloxystine from the aphid Uroleucon which he identified as this species by comparison with the type. We in the UK, and Wolfgang Völk1 and Gerhard Hubner (pers. comm.) in Germany, have reared morphologically similar forms from Uroleucon species that differ, especially in colour, from rare victrix sensu stricto attacking the same host. We sequenced specimens from both countries.

(iii) tscheki Giraud. Alloxystines reared from Cryptomyzus spp. on Ribes have been called tscheki. We obtained specimens from Germany reared from this host which we found to be morphologically identical to the most common alloxystine in our study site which in Müller et al. (1999) is called Alloxysta v2 and is reared exclusively from the aphid Capitophorus carduinis on Cirsium. We also sequenced a specimen reared from a very different host, the spruce aphid Elatobium abietinum, that again we could not distinguish morphologically. $A$. tscheki was excluded from the British faunal list by Fergusson (1986).

(iv) fuscicornis Hartig. One of the most frequently studied alloxystines is the hyperparasitoid of the cabbage aphid (Brevicoryne brassicae) through the primary parasitoid Diaeretiella rapae. In the older literature it was known as Charips brassicae Ashmead but it was synonymised with infuscata Kieffer (originally described as a variety of victrix) by Evenhuis (1972) and then later both names were synonymised with fuscicornis (Evenhuis, 1982). Fergusson (1986) synonymised fuscicornis with victrix. We sequenced specimens from two localities in the UK, and one in Germany. 


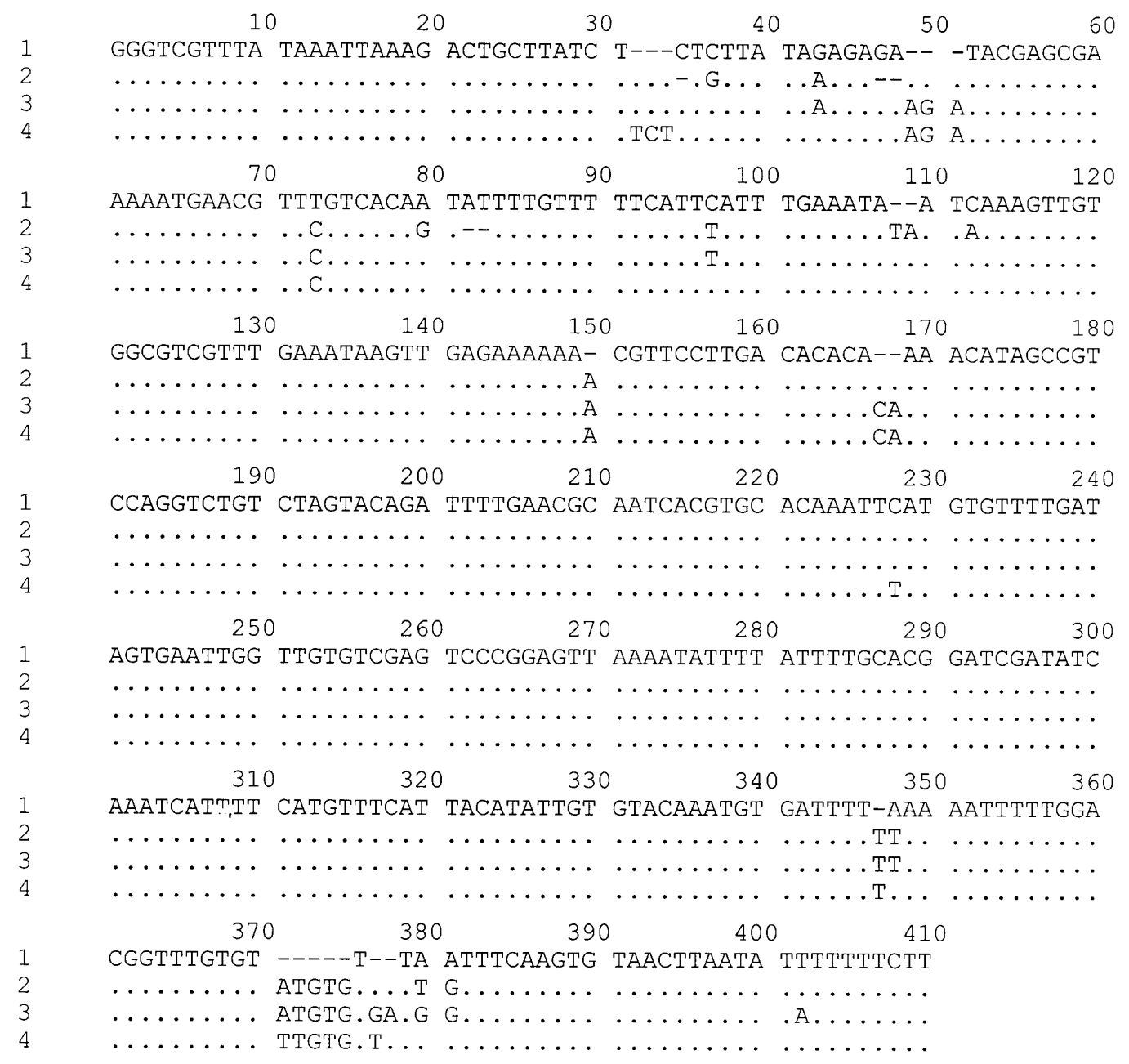

Fig. 1. Aligned sequences of the four alleles of ITS2 that were observed in the Alloxysta victrix group. The alleles correspond to the putative species as follows: $1=A$. victrix; $2=A$. leunisii; $3=A$. fuscicornis; $4=A$. tscheki (EMBL accession numbers: AJ309962-5). The lengths are 391, 395, 405 and 407 bp respectively.

Parasitised aphids were collected in the field and placed in gelatine capsules for rearing in the laboratory. Specimens for sequencing were placed in $100 \%$ ethanol within 24 hours of emergence and came from temporally and/or spatially separated samples to ensure they were not siblings.

\section{Molecular techniques and primers}

DNA was extracted from the metasoma of single specimens using the DNeasy kit (Qiagen) with final elution into $30 \mu \mathrm{l}$ water. Following initial amplifications using primer sequences in Campbell et al. (1993), we obtained complete ITS2 sequences using the following primers situated in the 3 ' end of the $5.8 \mathrm{~S}$ sub-unit and the $5^{\prime}$ end of the $28 S$ sub-unit respectively: forward = ATT CCC GGA CCA CGC CTG GCT GA; reverse = CGC CTG ATC TGA GGT CGT C (written 5' to 3').

PCRs were carried out in a GeneAmp 9700 thermal cycler in $50 \mu \mathrm{l}$ reactions containing $1.0 \mu \mathrm{l}$ DNA extract, $20 \mathrm{pmol}$ primers, $10 \mathrm{nmol}$ dNTPs (Amersham Pharmacia Biotech; APB), 1.5 units Taq polymerase (Roche) and $5.0 \mu \mathrm{Taq}$ buffer (containing 1.5 $\mathrm{mM} \mathrm{MgCl} 2$ ). Cycle conditions were $94^{\circ} \mathrm{C}$ for $30 \mathrm{sec} ; 44^{\circ} \mathrm{C}$ for $30 \mathrm{sec}$ and $72^{\circ} \mathrm{C}$ for $1 \mathrm{~min}(35 \mathrm{cycles}$, plus an initial denaturation for $2 \mathrm{~min}$ and a final extension for $7 \mathrm{~min}$ ). Products were cleaned using GFX gel band purification (APB) and then sequenced directly using dye terminators on an ABI 3700 automated sequencer using 1/4 recommended volumes (PE Biosystems).

\section{RESULTS}

Four different alleles were identified among the 28 specimens sequenced (EMBL accession numbers: AJ309962-5). The aligned sequences of these alleles are shown in Fig. 1. The species provisionally classified as $A$. victrix, A. leunisii, A. tscheki and $A$. fuscicornis each possessed a unique allele with no intraspecific variation. In the three cases where we studied specimens from both the UK and Germany, the wasps from the two countries had identical sequences.

Is it possible that these results could have been obtained by chance if the null hypothesis is that the specimens belonged to a single interbreeding population? Consider only the $11 \mathrm{~A}$. victrix (10 females, 1 male) and $5 \mathrm{~A}$. tscheki (4 females, 1 male) collected at Silwood Park. Because the differences between the "victrix" and "tscheki" alleles are mainly indels (Fig. 1) diploid heterozygote females would have been identified (the pherograms would become unreadable after the site of the first indel) but none were found. If they were part of a single interbreeding population then our best estimate from these data of the frequency of the "victrix" allele is 0.7 
TABLE 2. Pair wise probabilities of the observed data under the null hypothesis of interbreeding populations. See text for a full explanation.

\begin{tabular}{l|ccc}
\hline & victrix & tscheki & fuscicornis \\
\hline tscheki & $5 \times 10^{-8}$ & & \\
fuscicornis & $3 \times 10^{-4}$ & 0.003 & \\
leunisii & $2 \times 10^{-5}$ & $5 \times 10^{-4}$ & 0.01 \\
\hline
\end{tabular}

(this estimate takes into account that in Hymenoptera females are diploid and males haploid). The probability that a female is homozygous "victrix" is thus 0.49 and homozygous "tscheki" 0.09 . The probability of the observed data based on the assumption of a single interbreeding population is $(0.49)^{10}(0.09)^{4}=5 \times 10^{-8}$. Applying this calculation to the other five pair wise comparisons reveals that the probability always falls well below the 0.05 significance level (Table 2). It is important to note at this point that this analysis is based on the biological species concept and is possible because these four species occur sympatrically. This approach cannot be used to infer species status for geographically isolated populations.

\section{DISCUSSION}

Our molecular analyses firmly support the more diverse view of alloxystine taxonomy championed by Evenhuis and co-workers. The group appears to be relatively species rich and composed of taxa that differ only in subtle morphological and colour characters. Although the application of traditional morphological species concepts can work in this group, the molecular data is critical for providing independent evidence for their validity. It is clear that $A$. fuscicornis (Hartig), A. leunisii (Hartig) and $A$. tscheki (Giraud) are valid names and should not be considered synonyms of $A$. victrix (Westwood). Our results confirm that the potential for apparent competition mediated by Alloxystinae was not underestimated by Müller et al. (1999), as would have been the case had the Fergusson (1986) concept of $A$. victrix proven correct.

Of the species we studied, $A$. fuscicornis and $A$. leunisii appear to be specialists on $D$. rapae attacking $B$. brassicae, and $A$. funebris attacking Uroleucon spp., respectively. We have reared no other alloxystine from $D$. rapae and just a single $A$. victrix from $A$. funebris, which was sequenced. Confirmation of the distinctness of these two species suggests that it is worth testing the hypothesis that they have specialised on these hosts and competitively exclude other hyperparasitoids (these species are attacked by other secondary parasitoids, but only those with a different life history that attack the primary parasitoid after it has mummified the aphid). B. brassicae is a major pest of brassicas hence the interest shown in A. fuscicornis biology (Nahif \& Madel, 1990; Ayal \& Green, 1993). It is common throughout the world wherever brassicas are grown (Evenhuis, 1974; Andrews, 1978; Carver, 1992) and may be responsible for the poor performance of $D$. rapae as a biological control agent. Our results showing A. fuscicornis to be a specialist demonstrate that nearby non-cruciferous crops and weeds are unlikely to act as a source of hyperparasitoids that may affect $D$. rapae populations.

A. tscheki and $A$. victrix are more polyphagous species, and while we cannot exclude the possibility that they contain more cryptic taxa that are not revealed by the ITS2 sequence, the available molecular and morphological evidence clearly points to each being a distinct species. $A$. tscheki is a common hyperparasitoid on two closely related aphid genera (Capitophorus feeding on Cirsium and Cryptomyzus on Ribes) but its third host, Elatobium, though also in the Macrosiphini is not considered closely related (Heie, 1992; Heie, 1995) and its host plant (Picea) is very different. The primary parasitoid attacking Elatobium (Aphidius schimitscheki) is however a close relative of $A$. matricariae, the primary parasitoid of Capitophorus (Starý, 1973). A. victrix has the widest host range in the genus and has also been studied closely because of its role as a hyperparasitoid of aphids feeding on various crops (Micha et al., 1993; Grasswitz \& Reese, 1998; Petersen et al., 2000). Unlike the case of A. fuscicornis, our results do suggest that neighbouring crops and weeds may harbour populations of the secondary parasitoid that might interfere with aphid biological control. Despite the consistent intraspecific variation in $A$. victrix associated with host size, we found no evidence that these forms were distinct species (though we have only studied specimens from a small fraction of the species' host range). Further evidence for the unity of the species is the observation that wasps collected from the aphids Microlophium carnosum and Macrosiphum rosae readily mated and accepted Aphidius ervi attacking Acyrthosiphon pisum as a host (unpublished data). Although $A$. tscheki and $A$. victrix are both polyphagous on larger spatial scales, in our long-term study community only $A$. victrix has multiple hosts (Müller et al., 1999) and is thus a candidate species to mediate indirect population effects amongst its hosts.

The ITS gene regions have been commonly used to used to detect species boundaries where morphology is suspect (Cornel et al., 1996; Van Oppen et al., 2000). Our study further demonstrates the usefulness of this region for this purpose, particularly when combined with testing a priori hypotheses derived from population genetic models (Sites \& Crandall, 1997). Our results are clear-cut because of the observed lack of intraspecific variation in ITS2 among our insects. This pattern, possibly due to concerted evolution (Brown et al., 1972; Zimmer et al., 1980; Elder \& Turner, 1995), combined with the relatively fast rate of evolution of ITS2 (Navajas et al., 1998) makes this region ideally suited for detecting cryptic species. However, intraspecific and even intragenomic heterogeneity have been reported in the ITS regions of some taxa (Vogler \& Desalle, 1994; Onyabe \& Conn, 1999; Beebe et al., 2000). What these different patterns of variation may be telling us about the population structures of the various organisms is unclear and requires a better understanding of the molecular mechanisms involved.

ACKNOWLEDGEMENTS. This work was funded by the Natural Environment Research Council and a Marie Curie grant 
from the European Commission. Wolfgang Völkl and Gerhard Hübner kindly collected the German specimens.

\section{REFERENCES}

ANDREWS F.G. 1978: Taxonomy and host specificity of nearctic Alloxystinae, with a catalog of the world species (Hymenoptera: Cynipidae). Occ. Pap. Entomol., Calif. Dept. Food Agric. 25: 128 pp.

Atanassova P., Brookes C.P., Loxdale H.D. \& Powell W 1998: Electrophoretic study of five parasitoid species of the genus Aphidius (Hymenoptera: Braconidae), including evidence for reproductively isolated sympatric populations and a cryptic species. Bul. Entomol. Res. 88: 3-13.

Avise J.C. 1994: Molecular Markers, Hatural History and Evolution. Chapman \& Hall, New York - London, 511 pp.

AYAL Y. \& GREEN R.F. 1993: Optimal egg distribution among host patches for parasitoids subject to attack by hyperparasitoids. Am. Nat. 141: 120-138.

Beebe N.W., Cooper R.D., Foley D.H. \& Ellis J.T. 2000: Populations of the south-west Pacific malaria vector Anopheles farauti s.s. revealed by ribosomal DNA transcribed spacer polymorphisms. Heredity 84: 244-253.

Brown D.D., Wensink P.C. \& Jordan E. 1972: A comparison of the ribosomal DNAs of Xenopus laevis and Xenopus Mülleri: Evolution of tandem genes. J. Mol. Biol. 63: 57-73.

Campbell B.C., Steffenn-Campbell J.D. \& Werren J.H. 1993 Phylogeny of the Nasonia species complex (Hymenoptera: Pteromalidae) inferred from an internal transcribed spacer (ITS2) and 28S rDNA sequences. Insect Mol. Biol. 2: 225-237.

CARver M. 1992: Alloxystinae (Hymenoptera: Cynipoidea: Charipidae) in Australia. Invert. Taxonomy 6: 769-785.

Cornel A.J., Porter C.H. \& Collins F.H. 1996: Polymerase chain reaction species diagnostic assay for Anopheles quadrimaculatus cryptic species (Diptera: Culicidae) based on ribosomal DNA ITS2 sequences. J. Med. Entomol. 33: 109-116.

EldER J.F. \& TuRNer B.J. 1995: Concerted evolution of repetitive DNA-sequences in eukaryotes. Quart. Rev. Biol. 70 : 297-320.

EvenHurs H.H. 1972: Studies on Cynipidae Alloxystinae 2. The identity of some species associated with aphids of economic importance. Entomol. Ber. 32: 210-217.

Evenhurs H.H. 1974: Studies on Cynipidae Alloxystinae 4 Alloxysta macrophadna (Hartig, 1841) and Alloxysta brassicae (Ashmead, 1887). Entomol. Ber. 34: 65-168.

EvenHurs H.H. 1982: A study of Hartig's Xystus species with type designations and new synonyms (Hymenoptera: Cynipidae Alloxystinae and Charipinae). Spixiana 5: 19-29.

Evenhrurs H.H. \& Barbotin F. 1987: Types des especes d'Alloxystidae (Hymenoptera: Cynipoidea) de la collection Carpentier, decrits par J.-J. Kieffer, avec synonymes nouveaux et un nomen novum. Bull. Annls. Soc. Roy. Belge Entomol. 123: $211-224$.

Fergusson N.D.M. 1986: Charipidae, Ibaliidae and Figitidae (Hymenoptera: Cynipoidea). Handbooks for the Identification of British Insects, Royal Entomological Society of London, London, $55 \mathrm{pp}$.

Godfray H.C.J. 1994: Parasitoids. Behavioral and Evolutionary Ecology. Princeton University Press, New Jersey, 473 pp.

Grasswitz T.R. \& ReEse B.D. 1998: Biology and host selection behaviour of the aphid hyperparasitoid Alloxysta victrix in association with the primary parasitoid Aphidius colemani and the host aphid Myzus persicae. Biocontrol 43: 261-271.
HeIE O.E. 1992: The Aphidoidea (Hemiptera) of Fennoscandinavia and Denmark. IV Family Aphididae: Part 1 of Tribe Macrosiphini of Subfamily Aphidinae. Fauna Entomologica Scandinavica, E.J. Brill, Leiden, 189 pp.

Here O.E. 1995: The Aphidoidea (Hemiptera) of Fennoscandinavia and Denmark. VI Family Aphididae: Part 3 of Tribe Macrosiphini of Subfamily Aphidinae. Fauna Entomologica Scandinavica, E.J. Brill, Leiden, 222 pp.

Holt R.D. 1977: Predation, apparent competition and the structure of prey communities. Theor. Popul. Biol. 12: 197-229.

Knowlton N. 2000: Molecular genetic analyses of species boundaries in the sea. Hydrobiologia 420: 73-90.

Menke A.S. \& Evenhurs H.H. 1991: North-American Charipidae - key to genera, nomenclature, species checklists, and a new species of Dilyta Förster (Hymenoptera: Cynipoidea). Proc. Entomol. Soc. Washington 93: 136-158.

Micha S.G., Stammel J. \& Holler C. 1993: 6-methyl-5heptene-2-one, a putative sex and spacing pheromone of the aphid hyperparasitoid, Alloxysta-victrix (Hymenoptera, Alloxystidae). Eur. J. Entomol. 90: 439-442.

Müller C. B., Adriaanse I.C.T., Belshaw R. \& Godfray H.C.J. 1999: The structure of an aphid-parasitoid community. $J$. Anim. Ecol. 68: 346-370.

NAHIF A.A. \& MADEL G. 1990: Biology of Alloxysta (= Charips) fuscicornis [Hym.: Charipidae], a hyperparasitoid of Diaeretiella-rapae [Hym.: Braconidae] in West-Germany. Entomophaga 35: 641-651.

Navajas M., Lagnel J., Gutierrez J. \& Boursot P. 1998: Species-wide homogeneity of nuclear ribosomal ITS2 sequences in the spider mite Tetranychus urticae contrasts with extensive mitochondrial COI polymorphism. Heredity 80: 742-752.

ONYABE D.Y. \& CONN J.E. 1999: Intragenomic heterogeneity of a ribosomal DNA spacer (ITS2) varies regionally in the neotropical malaria vector Anopheles nuneztovari (Diptera: Culicidae). Insect Mol. Biol. 8: 435-442.

Petersen G., Matthiesen C., Francke W. \& Wyss U. 2000 : Hyperparasitoid volatiles as possible foraging behaviour determinants in the aphid parasitoid Aphidius uzbekistanicus (Hymenoptera: Aphidiidae). Eur. J. Entomol. 97: 545-550.

PunGerL N.B. 1986: Morphometric and electrophoretic study of Aphidius species (Hymenoptera: Aphidiidae) reared from a variety of aphid hosts. System. Entomol. 11: 327-354.

Sites J.W. \& Crandall K.A. 1997: Testing species boundaries in biodiversity studies. Conser. Biol. 11: 1289-1297.

STARÝ P. 1973: A review of the Aphidius-species (Hymenoptera: Aphidiidae) of Europe. Annot. Zool. Botan. 84: 1-85.

Van Oppen M.J.H., Willis B.L., Van Vugt H. \& Miller D.J. 2000: Examination of species boundaries in the Acropora cervicornis group (Scleractinia, Cnidaria) using nuclear DNA sequence analyses. Mol. Ecol. 9: 1363-1373.

Vogler A.P. \& Desalle R. 1994: Evolution and phylogenetic information-content of the Its- 1 region in the tiger beetle Cicindela dorsalis. Mol. Biol. Evol. 11: 393-405.

WATERS J.M., ESA Y.B. \& WALlIS G.P. 2001: Genetic and morphological evidence for reproductive isolation between sympatric populations of Galaxias (Teleostei: Galaxiidae) in South Island, New Zealand. Biol. J. Linnean Soc. 73: 287-298.

Zimmer E.A., Martin S.L., Beverley S.M. \& Kan Y.W. 1980: Rapid duplication and loss of genes coding for the a chains of hemoglobin. Proc. Nat. Acad. Sci. USA 72: 1354-1358.

Received October 21, 2002, revised February 3, 2003; accepted February 12, 2003 